\title{
Media labs-creative cooperation and mutual learning: Case studies across Europe
}

\author{
Marta du Vall ${ }^{1, *}$, and Marta Majorek $^{2}$ \\ ${ }^{1}$ Andrzej Frycz Modrzewski Krakow University, Herlinga - Grudzińskiego 1, Kraków 30 - 705, \\ Poland \\ ${ }^{2}$ Andrzej Frycz Modrzewski Krakow University, Herlinga - Grudzińskiego 1, Kraków 30 - 705, \\ Poland
}

\begin{abstract}
The idea of a media lab is not strictly defined. Media labs, in general, are experimental projects combining creative, research and education activities. As some researchers have concluded, "Media lab is not a name, only a tag that you can describe a specific type of place and as with tags - use freely, according to and contributing to its conceptual meaning." The study will present the most contemporary, important theoretical issues regarding media labs which, by creating a platform for exchanging experience and knowledge between people representing different professional groups, such as programmers, culture animators and academic researchers, enable work on projects seeking convergence of knowledge, multimedia and technology. The authors will also focus on case studies to indicate the wide range of possibilities for applying this model of creative cooperation.
\end{abstract}

Key words. digital tools, media lab, education, cooperation, knowledge, technology

\section{What is a media lab?}

At the beginning, it is worth noting that there is no precise definition of a media appealing because its impreciseness, which is not reckless, makes it open and ready to respond dynamically to change. Furthermore, there is no single media lab model. The simplest definition, which we can find on the internet reads that "A media lab is a form of institution that enables joint work and learning by people with different skills over projects that use new media and technologies." [1] It is assumed that by intensifying the exchange of experience and knowledge between people representing various professional groups (artists, designers, programmers, cultural animators, academic researchers), it is possible to work on projects which strive to converge multimedia and technology.

Some researchers claim that the idea of a media lab is so appealing because its impreciseness, which is not reckless, makes it open and ready to be able to respond

\footnotetext{
* Corresponding author's e-mail: mduvall@afm.edu.pl
} 
dynamically to change. Media lab is not a name, only a tag that can be used to describe a specific type of place and it can be used freely. [2]

The concept of a media lab is associated with the idea of "Makers" which is propagated by Dale Dougherty. In his TED Talk [3], Dougherty claims that all people are makers. We all have the ability to make and create things. Makers are enthusiasts, who today harvest the technology from places around us and create and explore new areas. Makers are sources of innovation. Dougherty, in his article in "Make", wrote: "More than mere consumers of technology, we are makers, adapting technology to our needs and integrating it into our lives". [4] Dougherty claims, and he is not alone, that the idea of makers should be propagated in education. It is hard to disagree. School should develop creativity - giving young minds the possibility to plan an action and its implementation, even if it fails. A teacher should stand aside, but also be an active observer and respond to each call by advising students or talking to them about the causes of failures. [5]

A media lab, as an idea, can be treated as an experimental educational laboratory. It is worth referring to Grzegorz Stunża's (Polish researcher and media educator) analysis here [6]:

- A media lab is primarily education about and using new media.

- Workshop activities of media labs should be treated as critical and dialogic education. They focus on awakening critical awareness.

- Another thing is freedom of projects implemented by media labs, which manifests in the possibility of benefiting from the experiences of other participants interested in similar activities.

- Activities integrating people who are interested in cooperation and in the idea of a media lab, as well as the media lab's community with the local community, have the dimension of educational exchange.

- Idea of a media lab stands in opposition to the "traditional" pedagogy of the school, where hierarchical communication is still dominant, focused on gathering knowledge. Variability of position in the course of education - transitivity of the role of a teacher and a student is an extremely important and creative experience, not yet explored by numerous institutions.

Returning to the main thread of the deliberations, media labs sometimes pose sources of real technological innovation; they also generate new forms of art and creativity. [7] A media lab is a type of institution that combines innovative trends developed in the field of culture and science with technology and the idea of creative workshops. As we can read on the website of the oldest media lab: "In a world where radical advances in technology are taken for granted, media lab researchers design technologies for people to create a better future". [8] In general, we can describe a media lab as an experimental project combining creative, research and education activities. It helps to bring ideas (even those seemingly crazy at first) into reality.

It is recognized that the first media lab in the world was established as the Department of Architecture and Urbanism School which is a part of the Massachusetts Institute of Technology. The MIT Media Lab was founded by professor Nicholas Negroponte and former rector of the university Jerome Wiesner in 1985. As we can read on the CBS NEWS website "for more than 30 years, MIT has been recruiting people with crazy ideas to work in their media lab, where life-changing inventions are created". [9] noteworthy are The following fragments from the mentioned article published on the CBS News website perfectly reflecting the ideas of a media lab are noteworthy:

"The Media Lab is this glorious mixture, this renaissance, where we break down these formal disciplines and we mix it all up and we see what pops out". 
'Ideas are the currency of MIT's Media Lab. The lab is a six-story tower of Babel where 230 graduate students speak dialects of art, engineering, biology, physics and coding, all translated into innovation".

"We really select for people who have a passion. We don't have to tell them to work hard. We have to tell them to work less hard and to get sleep, occasionally."

"The uncommon growth of the Media Lab flows from its refusal to be bound to goals, contracts, or next quarter's profits. It is simply a ship of exploration going wherever a crazy idea may lead."

On the MIT Media Lab website, under A Unique Perspective tab we can find the following information: "The MIT Media Lab is a unique resource to help companies address these issues via its facilities and faculty, which support more than 25 research groups and initiatives and more than 450 projects, ranging from smart prostheses for amputees, to creative computation for kids, to designing cities of the future. Broad research foci include synthetic neurobiology, digital currencies, extended intelligence, wellbeing, affective computing, innovative interfaces, and sociable robots". [10] In turn, the The MIT Media Lab at a Glance tab reads as follows: „The MIT Media Lab transcends known boundaries and disciplines by actively promoting a unique, antidisciplinary culture that emboldens unconventional mixing and matching of seemingly disparate research areas". [11]

It is not difficult to see that the idea of a media lab makes it possible to create new quality, new technologies, convergence of media and technology through joint work on projects. All these give the opportunity to create modern teaching methods and techniques. The media lab is deeply rooted in the idea of media education, which assumes not only the ability to critical reception of media messages, but also to participate in the creation of content. Media labs can be treated as a new approach to new media and new technologies that are increasingly absorbing most of us. It is also necessary to mention that, unfortunately, numerous education systems fail to keep up with the new media and technological novelties. Hence, the idea of a media lab, as a kind of fun and experimenting, seems to be particularly interesting. Media lab is for all those who the idea of cooperation is close for. It gives opportunities to try one's own skills in practice in an interdisciplinary team, acquiring new competences and implementing some exceptional projects. Everyone can participate in media lab's activities, regardless of their education or age. The media lab is characterized by its anti-disciplinary nature. Antidisciplinarity requires that media lab participants have different competences and skills. It is assumed that each participant has specific knowledge and skills and is expected to actively use them in the educational process. Combining various points of view and competences serves to open the hermetic worlds of individual disciplines. [12] The idea of a media lab changes the perspective from Do It Yourself (DIY) to Do It Together. The media lab combines social activism, education and technology. It creates some space for experiment and cooperation, sharing knowledge and searching for solutions.

While closing the subject of the general definition of a media lab, it is worth noting that the activity described in the article can also be defined by other terms, such as: Fablab, Futurelab, Thinklab, Idealab, Hackerspace. We could also describe it as simply as workshops or laboratories. We can refer all the indicated terms to the new spaces of cooperation and creativity. Kevin Flanagan recalled: „Whether you were born into the networks or simply interested in digital creation, nowadays there are places and communities where you can learn, create and share knowledge. These laboratories (labs) are mediation spaces dedicated to practice, expression and creation as much as critical commitment on the role of technology in art and society. Individual users, artists, engineers, researchers and designers go there to research and produce in the free culture spirit". [13] 


\section{Case studies - media labs in Europe}

One of the most popular media lab in Europe is MediaLab Prado. It is ,a citizens' laboratory that serves as a place of encounter for the production of open cultural projects. Anybody can make proposals or sign up for proposals made by someone else and carry them out on a collaborative basis. Activities are structured around work groups, open calls for the production of projects, collaborative research and learning communities that address a very wide range of topics". [14] The main goals which have been set are: building, promoting and sustaining learning and hands-on communities which see people from highly different worlds (in terms of education and experience, interests, background or social status) work together on development of specific projects; improving and evaluating collaborative work methodologies and modus operandi at various levels of action: institutional in general, within the organization itself and in users' development of projects. The MediaLab Prado consists of six thematic laboratories: Creative Prototyping Lab, Collective Intelligence Laboratory for Democratic Participation, Citizen Innovation Lab, Open Data Lab, Citizen Science Lab, Audio/Video Experimentation Lab. It is worth indicating selected programmes implemented in MediaLab Prado. From the authors' point of view, Collective Intelligence for Democracy programme seems to be very interesting. „During a period of fifteen days, ten multidisciplinary teams participate in the workshop of Collective Intelligence for Democracy, creating prototypes to activate collective intelligence, improving democracy and citizen commitment". [15] Another interesting programme is Inclusiva-net. It ,is a platform dedicated to the research, documentation, and circulation of network culture theory. Its main study and documentation areas are the processes of social and cultural inclusion of telecommunication networks and their effects in the development of new artistic practices and critical knowledge production". [16]

The Digital World Research Centre [17] is a research network at the University of Surrey. It brings engineering, communication, social science, business, design and arts together to work on media innovation projects which have some particular impact on the society and culture. The Center conducts interdisciplinary research into new media platforms, content and experiences, and strives to commercialize and apply the research findings in the society. The main focus in on understanding new forms of digital media production and consumption, and on developing ways of supporting them with novel media genres, formats, devices and services. Currently, the Center is carrying out, among others, the following projects: Media parcels: facilitated media sharing to promote feelings of social connectedness in older adults. As we can read on project website „This project is a collaborative research activity and network between the University of Surrey, University of Sao Paulo (USP) and Federal University of Sao Carlos UFSCAR). It tries to fill a gap in the research and development of mobile device applications for older users, including tools for assisted living, monitoring, e-health care and wellbeing". [18]

In the Netherlands, the Hackastory is worth mentioning, which main purpose is to teach coders and journalists how to collaborate. Hackastory refers to the previously mentioned idea suggested by Dougherty. We can read what follows on the media lab website: „We are doers. We get things done for you". [19] The founder of Hackastory emphasizes that the main activity is organization of the Hackathons journalism where multidisciplinary teams of designers, coders and journalists work together. The Hacakstory team has created a very interesting thing - namely a handpicked list of tools and resources to help build digital story. [20] It provides some information and links to useful applications helpful in creating various kinds of materials: multimedia, infographic, mapping, video, photo, audio, mojo, data, verification, social media, VR, animation, design. There are also such tabs as: library, inspiration and brainstorm. 
NxtMedia, a Norwegian technology cluster [21], conducts activities aimed at stimulating journalism innovation through encouraging partnerships, research and product development across international media, technology and academic boundaries. Rolf Dyrnes Svendsen, an editor and a chairman at NxtMedia claims that this media lab is driven by two priorities: networking and enabling. Members of the network are focused on common goals or interest areas, and supported in finding opportunities and resources to implement the projects. Svendsen explains that the process "identifies possibilities according to partner's and member's interests and accelerates projects from idea to execution". [22]

In turn, in one of the Polish media lab - Medialab Katowice - participants of interdisciplinary projects carried out at the point where art, design and technology meet, use digital media to study the city and create new narratives for the city of Katowice. The project includes workshops, interventions in the public space, exhibitions, lectures and discussions. The medialab's activities take place in several thematic blocks: Shared Cities, Data Science, BudgetsLab, ByteLab and Kosciuszko's project. [23] A particularly interesting project implemented by the Medialab Katowice was Urban Data Stories - ,an interdisciplinary meeting of designers, developers, planners, activists, journalists and all others interested in the acquisition, processing and analysis of data to create meaningful stories about the city". [24] The Medialab Katowice follows the cultural activity in the city by collecting, studying and visualizing data on participants of cultural events and social media users. [25]

Designers, engineers and psychologists work together in the media lab located in Lausanne, France. The EPFL+ECAL Lab aims to explore the potential of emerging technologies through design research. As we can read on the lab's website [26]: it fosters innovation at the crossroads between technology, design and architecture. The EPFL-ECAL $L a b$ bases its ,activities along three axes: giving new meaning to technologies, fueling innovation by widening the scope of designers' work and forming new links between research and applications for society". [27] The worth mentioning projects are among others e.g. Solidarity Network - its aim is to give digital technologies a social purpose for older people; Massive is Light - it offers digital solutions to manage big data for everyday use; La Porte des Savoirs - it focuses on experience of immersion and information flow; Give me more - its purpose is to change the relationship between the physical and digital worlds.

A media lab located in Greece carries out an interesting and important activity. The InVID project embarked on a mission to create a platform to detect, authenticate and check the reliability and accuracy of newsworthy video files and video content spread via social media. [28] In response to the growing attention for the fake news problem, InVID released a free browser plug-in to help journalists verify images and videos and to debunk fake video news - the InVID Verification Plugin. [29] The plugin code has been provided in open source under a MIT license. Making the tool as widely available as possible allows to get feedback from users, so products can be improved. [30] In turn, the InVID Verification Application is a web-based integrated toolset for the verification of videos and their context. [31] The InVID Multimodal Analytics Dashboard is a visual search and information exploration platform to identify and track evolving stories across multiple social media platforms - including participating actors (persons, organizations) and the relations among them. [32] Some examples of the use of tools created by the InVID team can be found on the project website. 


\section{Conclusion}

As it has been shown above, media labs can cover a wide spectrum of activities. They can also successfully generate a wide range of pedagogical activities - from artistic education, through education in the use of technology, construction of new technological solutions, music education, historical education and any other, through a combination of the theory of action developed in the dialogue, implementation based on various, often open source media tools. [33]

The media labs indicate the direction which changes in the education system should go in. The modern education systems should give the choice (freedom), be personalized (adapted to each student individually), transparent and reliable (and therefore respond to the need for criticism and give a sense of integrity with the student's experience); they should also allow for cooperation in a group and be fun, and also take advantage of speed and innovation (in terms of methods and tasks). [34]

The change of thinking is made due to the social need and maladjustment of the education system to the dynamics of cultural and communication changes under the pressure of new technologies. The most important factor influencing the attractiveness of the media lab idea is its bottom-up character, flexibility and openness to various environments, especially from outside of the academy or the field of education. The media labs are often educational and cultural institutions which are rooted in the need to jointly develop some interests of certain individuals, with the desire to create a place for meetings for people working together on the web on specific projects. [35] Undoubtedly, the possibilities of practical use of digital tools by all (not only young) people in educational, cultural, social and technological projects are an investment in the future. The media labs, despite being on the margin of the academy and the education system, can be tools for change. They indicate new patterns of action, new ways of thinking and new forms of cooperation.

\section{References}

1. Wikipedia. Available at: https://pl.wikipedia.org/wiki/Media_Lab (2018)

2. M. Filiciak, A. Tarkowski, Medialab.a sprawa polska. in: M. Filiciak, A. Tarkowski, A. Jałosińska, Medialab. Instrukcja Obstugi. Chrzelice, p. 11-12 (2011).

3. D. Dougherty, TED Talk. Available at: https://www.ted.com/talks/dale_dougherty_we_are_makers (2011)

4. D. Dougherty, The makers of Make, Make vol. 1, p. 7 (2005)

5. G. Tulley, TED Talk. Available at: https://www.ted.com/talks/gever_tulley_s_tinkering_school_in_action (2009)

6. G. Stunża, Edukator Medialny. Available at: http://edukatormedialny.pl/2011/01/06/medialab-laboratorium-edukacji-medialnej/ (2011)

7. M. Filiciak, A. Tarkowski, Medialab.a sprawa polska. in: M. Filiciak, A. Tarkowski, A. Jałosińska, Medialab. Instrukcja Obstugi. Chrzelice, p. 13, (2011).

8. MIT Media Lab. (2018). Available at: https://www.media.mit.edu/about/missionhistory/ (2018)

9. S. Pelley, CBS News. Available at: https://www.cbsnews.com/news/mit-media-labmaking-ideas-into-reality-future-factory/ (2018)

10. MIT Media Lab. Available at: https://damprod.media.mit.edu/x/2018/05/24/Unique\%20Perspective\%20May\%202018_tNbz4 ms.pdf (2018) 
11. MIT Media Lab. Available at: https://dam-prod.media.mit.edu/x/2018/05/07/at-aglance.pdf (2018)

12. A. Słodownik, Dwutygodnik.com. Strona kultury. Available at: http://www.dwutygodnik.com/artykul/4912-medialaby-czyli-jak-mozna.html (2013)

13. K. Flanagan, $P 2 P$ Foundation. Available at: https://blog.p2pfoundation.net/medialabs-in-europe-mapping-places-and-networks/2014/10/12 (2014)

14. MediaLab Prado. Available at: https://www.medialab-prado.es/en/medialab/moreinfo/about (2018)

15. MediaLab Prado. Available at: https://www.medialabprado.es/en/programs/collective-intelligence-democracy (2018)

16. MediaLab Prado. Available at: https://www.medialabprado.es/en/programs/inclusiva-net (2018)

17. Digital World Research Center. Available at: https://www.surrey.ac.uk/digital-worldresearch-centre (2018)

18. Digital World Research Center. https://www.surrey.ac.uk/digital-world-researchcentre/funded-projects/uk-brazil-sprint-network-assistive-media-health-and (2018)

19. Hackastory. Available at: https://hackastory.com/about-hackastory/ (2018)

20. Hackastory. Available at: https://tools.hackastory.com/ (2018)

21. NxtMedia. Available at: https://nxtmedia.no (2018)

22. Media Innovation News. Available at: https://media-innovation.news/medialab/nxtmedia-a-collaborative-network-for-innovation/ (2018)

23. Medialab Katowice. Available at: https://medialabkatowice.eu/o-medialabie/ (2018)

24. Urban Data Stories. Available at:http://urbandatastories.eu/ (2018)

25. Blog. Medialab Katowice. Available at: https://blog.medialabkatowice.eu/en/ (2018)

26. EPFL-ECAL Lab. Available at: http://www.epfl-ecal-lab.ch/ (2018)

27. ibid

28. InVID Project. Available at: http://www.invid-project.eu/description/ (2018)

29. InVID Verification Plugin. Available at: http://www.invid-project.eu/invidverification-application/ (2018)

30. Media Innovation News. Available at: https://media-innovation.news/medialab/invid-video-verification-project-involving-developers-academics-journalists/ (2018)

31. InVID Verification Application. Available at: http://www.invid-project.eu/invidverification-application/ (2018)

32. InVID Multimodal Analytics Dashboard. Available at: http://www.invidproject.eu/invid-multimodal-analytics-dashboard/ (2018)

33. G. Stunża, Edukator Medialny. Available at: http://edukatormedialny.p1/2011/01/06/medialab-laboratorium-edukacji-medialnej/ (2011)

34. A. Maj, Medialaby, fablaby i banki wiedzy jako nowe modele instytucji edukacyjnych. Państwo i Społeczeństwo, vol.3, p. 94. (2017).

35. ibid. 